\title{
The Use of Zigs and Zags to Reduce Scarring over "Keloid Triangles" during Excisional Surgery: Biomechanics, Review and Recommendations
}

\author{
Sharad P. Paul \\ School of Medicine, University of Queensland, University of Auckland, Auckland University of Technology, Auckland, New Zealand \\ Email:sharad@sharadpaul.com
}

How to cite this paper: Paul, S.P. (2017) The Use of Zigs and Zags to Reduce Scarring Over "Keloid Triangles" during Excisional Surgery: Biomechanics, Review and Recommendations. Surgical Science, 8, 240-255. https://doi.org/10.4236/ss.2017.86027

Received: May 3, 2017

Accepted: June 16, 2017

Published: June 19, 2017

Copyright $\odot 2017$ by author and Scientific Research Publishing Inc. This work is licensed under the Creative Commons Attribution International License (CC BY 4.0).

http://creativecommons.org/licenses/by/4.0/

\begin{abstract}
Aim: The sternal region, cervico-mandibular region and the intra-mammary region have been the bane of many cutaneous surgeons, with a higher propensity for poor scarring and wound complications. In this article, the author undertakes a review of different methods of breaking up scars by utilizing zigs and zags, and conducts a pigskin study to measure the reduction in tension that can be achieved by using a simple zigzag technique while performing excisions. Methods: A pigskin study conducted into the use of the simple zigzag to reduce the tension (and thereby scarring) of surgical wounds is reported here, and comparison and review is undertaken of the biomechanics of elliptical excisions and traditional Z-plasties. Results: Using a simple zigzag reduces tension across the midpoint of the scar more effectively than a Z-plasty or a simple elliptical excision. Conclusion: The techniques of breaking up a scar or incision line by using zigs and zags, in a means to reduce scarring, are not new. However, each of these techniques has specific advantages and disadvantages that need consideration by the surgeon. In this paper, a pigskin study is conducted into the use of the simple zigzag to reduce the tension (and thereby reduce the risk of poor scarring) of surgical wounds.
\end{abstract}

\section{Keywords}

Keloid, Hypertrophic Scar, Scarring, Wound, Excision, Ellipse, Chest, Sternum

\section{Introduction}

The sternal region and the intra-mammary region has been the bane of many cutaneous surgeons, with a higher propensity for poor scarring and wound 
complications. West and others coined the term "keloid triangle" to indicate the suprasternal region where scars become especially conspicuous and prone to hypertrophic and keloid scarring [1]. To these regions, we should add the cervicomandibular region and the cervicothoracic regions (Figure 1). While the chest wall is exposed to multiple shearing forces due to limb movements, the weight of breast tissue also contributes to scar stretch and increased wound tension. The resultant mechanics of scar mechanotransduction, a term that has come to denote the conversion of mechanical stimuli into biochemical responses at different body sites remain unclear, and ultimately the resultant scar is largely determined by the biomechanical properties of skin itself [2] [3]. In humans and mammals, wounds heal by fibrotic scar formation, which provides early restoration of tissue integrity, as opposed to the functional regeneration that occurs in lower animals [4]. The continuum mechanics approach has shown to be of great use in understanding skin stretch, skin tension, and tissue expansion, especially on sites close to the bone such as the sternum and areas like the scalp [5]. When skin is stretched during the closure phase of excisional surgery, its expansion and tension are interrelated, and the relationship between this stretch and expansion works like this: the deformation gradient has an elastic and a growth part and therefore it is important to understand the biomechanics of skin tension at different sites and the signals it generates [6]. This signal of mechanotransduction involves proteins and molecules of the ECM, the cytoplasmic and nuclear membranes and the cytoskeleton, eventually affecting the nuclear chromatin at a genetic level [7]. The system that brings together all the levels of mechanotransduction and their influence on genetic cell programming has been termed "tensegrity", a portmanteau of tension and integrity [8].

Many groups have studied models of scarring using external application of mechanical stress on healing incisions-as mechanical force is the major factor in fibro-proliferative processes that cause tissue fibrosis and hypertrophic scarring [9]. Porcine skin anatomy is like human skin, and therefore pig models have

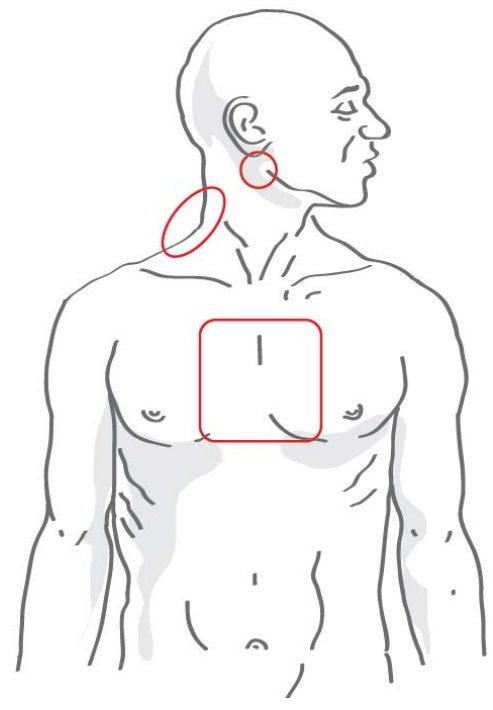

Figure 1. Keloid Zones on the body. 
been used by many authors to study human cutaneous mechanobiology, including in this study [2]. Gurtner and others have shown that scar formation in the red Duroc pig is very like that in humans, and the degree of post-injury fibrosis directly correlates with the amount of tension imparted on the wound during healing, and this fact influenced our choice of medium for this study [10]. While mechanotransduction involves stretch activated calcium-dependant ion channels [11], the tension in the wound generates cell traction forces in the cellular cytoskeleton that are then transmitted to the surrounding ECM or neighbouring cells [12].

Initial observations on keloid scars were made in burn wounds, with researchers noting that a wound that healed in less than 10 days had only $4 \%$ risk of developing hypertrophic scarring, whereas when a burn took 3 weeks to heal, the risk rises to $70 \%$ [13]. We know that the characteristic butterfly or dumbbell shape associated with keloids is determined by the direction of mechanical forces, and therefore an understanding of these forces, and reduction of wound tension is of great importance to reduce scar formation [14]. Authors of studies of mechanical forces on skin have concluded that reducing skin tension around wounds or scars is the most important step in reducing thick, unsightly scars [15].

The other approach to reducing the visibility of scars has been using a visual approach, rather than a mechanical one-proponents of geometric broken line repairs have written that such closures make "the scar less noticeable because the eye has more difficulty tracking this irregular, multiply segmented line [16]". But a review of the neuroscience of vision and optical illusions does not back up this claim. In fact, preliminary studies into sharp broken lines that occur after a Z-plasty or zigzag surgical procedure, suggest that they may be less pleasing to the eye. This was first noted in an important study by Stratton who used participants viewing different types of lines, only to conclude that eye movements that are required to follow sharp, broken lines must be more abrupt and, therefore, less pleasant than those required to follow curved lines [17]. On the other hand, some authors have proposed that zigzag lines indeed appear mobile and less visible in peripheral visual fields, and that a short line segment squirms along a zigzag line, even if this is only when viewed in one's peripheral vision [18]. In fact, certain authors have hypothesized an evolutionary origin to the visualization of sharp broken lines as a perception of danger or unpleasantness (shark teeth, for example) [19]. However, others have noted that when proposing an evolutionary origin, it is not enough to suggest a plausible explanation but a testable hypothesis is required [20]. That may be the best approach to take when planning excisional surgery in "keloid-zones" of the body. It has already been established that the most important factor to reduce scarring in scar-prone areas is the reduction of the maximal wound tension, and in this article the author undertakes a review of different methods of breaking up scars by utilizing zigs and zags and the implications for surgical wound closing tension. A pigskin study conducted into the use of the simple zigzag to reduce the tension (and 
thereby scarring) of surgical wounds is reported here, and a comparison is also undertaken with elliptical excision and Z-plasties (Figure 2).

\section{Z-plasty}

The history of the Z-plasty is rooted in oculoplastic surgery. The first recorded case was when William Horner, a surgeon at the Philadelphia Hospital, Blockley and Professor of Anatomy in the University of Pennsylvania, performed this procedure to repair an eyelid ectropion caused by burn scarring [21]. However, some reports attribute the first Z-plasty to Denonvilliers, who noted the usefulness of breaking up a scar-line into zigs and zags when he first described a Z-plasty-type procedure that he found useful, also for a blepharoplasty [22]. Denonvilliers had written about his plan thus: "I will free the lowered external angle of the eye by two incisions above and below the lid margins meeting at the angle. Then I will form above and a little external to the first triangle, a second triangle opposite to the first. This accomplished, I will raise the triangle involving the external corner of the eye and cause it to take the place of the second triangle that I will then bring down to take the place of the first" [23]. While this description seems apt for a Z-plasty, there were indeed no physical illustrations or images that were recorded during this operation to confirm. Stewart McCurdy, an American surgeon, then utilized the same method on the oral commissure-the first time the technique was described in America. McCurdy, who was Professor of Oral and General Surgery at the University of Pittsburgh, and Orthopaedic and Plastic Surgeon to Columbia and Presbyterian Hospitals is credited as being the first one to use the term "Z-plasty" when he published his article: "Z-plastic surgery: plastic operations to elongate cicatricial contractions of the neck, lips and eyelids and across joints [24]." Limberg, in 1966, famed for his rhombic flaps [25], also wrote extensively on the Z-plasty, although it would seem Limberg considered the term a misnomer-given that in the alphabetical "Z" all the limbs are equal, unlike in the surgical version [26]. Limberg favoured the term "transposed triangular flaps" [27] in his initial works to describe this technique, and later in his book described a full range of such procedures from equal angled flaps (where each flap moves equally), to flaps with unequal angles
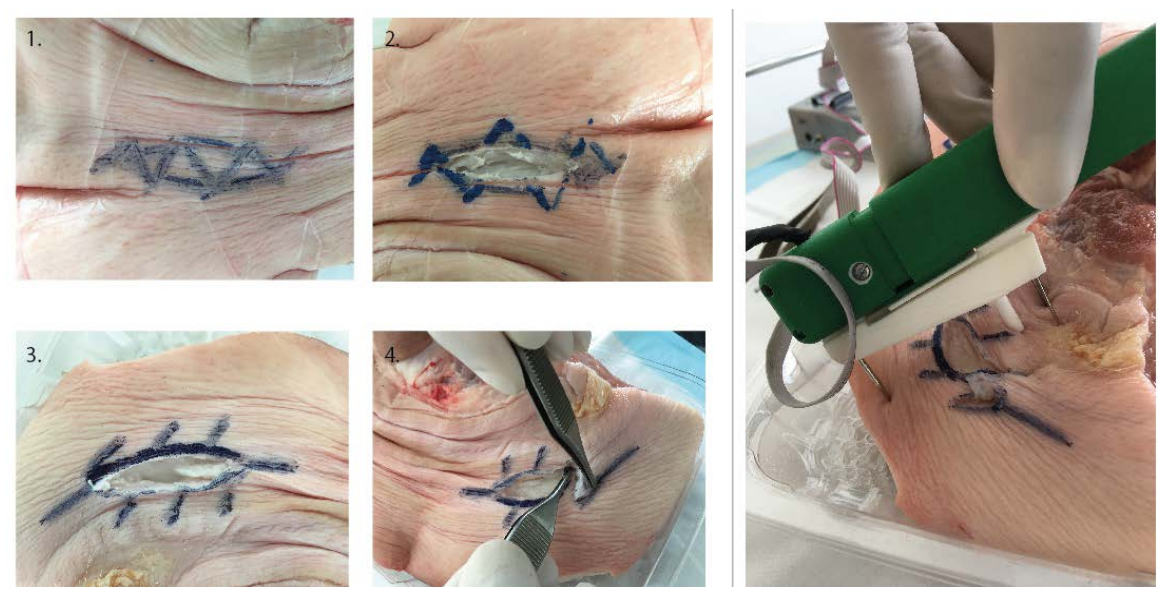

Figure 2. Wound tension testing of zigzags and Z-plasties on pigskin. 
(where the larger angled flap moves less) [28]. However, McCurdy's term, "Zplasty" endured.

Z-plasties can be planned in a single, multiple or serial fashion. When using the multiple Z-plasty in a serial fashion, the planned incisions run parallel to the limbs of the Z-plasty at either end of the scar. In this article the use of zigs and zags to reduce sternal scarring, and indeed scarring at other flexural areas at the jawline, neck or limbs is described. But using a Z-plasty in this situation can be problematic due to the lengthening it causes. Further, with the serial Z-plasty technique, as would be needed in a location such as the sternum, the flaps become 3-sided rhombic flaps, and not 2 -sided triangles. Now we can begin to understand the wisdom of Limberg's insistence of calling the procedure as transposed triangular flaps. Also, it must be noted that he limbs in between the 2 peripheral limbs become approximately twice the length of the limbs before transposition. Essentially, when it comes to a Z-plasty the angles of the limbs are important-it is known that using $30^{\circ}$ angles will increase the length by $25 \%, 45^{\circ}$ angles are associated with a $50 \%$ increase and $60^{\circ}$ angles increase the ideal length by $75 \%[16]$.

Let's consider a triangle with sides $\mathrm{a}, \mathrm{b}$ and $\mathrm{c}$ (and opposing angles $\mathrm{A}, \mathrm{B}$ and $C)$. In any triangle, if sides $a$ and $b$ and the angle $C$ are known, then side $c$ can be found by using the following formula [29]:

$$
c^{2}=a^{2}+b^{2}-2 a b \quad[\cos C]
$$

And, if the three sides a, b and $\mathrm{c}$ are known, then we find angle A using the following formula:

$$
\cos \mathrm{A}=\left(\mathrm{b}^{2}+\mathrm{c}^{2}-\mathrm{a}^{2}\right) / 2 \mathrm{bc}
$$

Using these formulas, we arrive at the conclusion that in a $60^{\circ} \mathrm{Z}$-plasty, the common limb rotates by $90^{\circ}$. The Figure 4 shows the degree of rotation of the common limb, and helps us design the correct Z-plasty depending on the location of the scar from a crease-line, and the degree of rotation needed to hide the scar. When it comes to Z-plasties where no lengthening is required, such as over the sternal region, the purpose of the $\mathrm{Z}$ is to equalize tension, with the preferred angle being $30^{\circ}$ for each limb of the $Z$.

Furnas described the four features of a Z-plasty thus [30]:

1) To increase (or decrease) length

2) To break up a straight line

3) To shift topographic features from one site to another

4) To efface or to create a web or a cleft.

However, one of the things to note in a Z-plasty is that the wider the angles of the triangular flaps Limberg described, the greater is the tension on the line of closure. In areas like the sternum, if we consider using a Z-plasty to break up a scar, we are left with the problem of alteration in length, as well as tension on the line of closure to consider. The fundamental benefit of a Z-plasty is its ability to lengthen a limb, and therefore correct a contracture. While plenty of studies have elucidated the angles and degrees of rotation and lengthening, there have 
been none that have specifically studied the reduction of tension in using a Z-plasty and that will be the focus of this review. There is an important matter to consider regarding Z-plasty in areas of thin, actinic-damaged skin on the face or burn scar contractures, as opposed to scar-prone areas on the chest. In the former, maximizing blood flow to the flaps is also a major objective; in the latter, the main consideration is reducing skin stress and tension. Some surgeons have suggested "rhomboid-to-W" technique, incorporating a W-plasty into other rhomboid defects or triangular flaps, and therefore this paper will also appraise the W-plasty in the next section.

\section{W-plasty}

When Borges elucidated the W-plasty technique, he basically considered the benefits as fourfold [31]:

1) Breaking up of the scar into smaller components

2) Redirecting anti-tension lines

3) Halving the depth i.e. the subcutaneous scar does not coincide with the zigzag cutaneous scar

4) Camouflaging scar by intermingling these small segments with other skin creases and wrinkles.

The W-plasty has proved to be very useful in areas like vermillion [32] or mental creases, has also been used in tracheal reconstruction [33], to repair stoma stenosis [34] and to break up scars of rotation flaps on the cheek [35]. The $\mathrm{W}$-plasty is primarily useful around labial regions, both oral [36] and perineal [37]. It has also been used primarily during repair of lacerations in these sites [38]. However, when used as a means of primary closure after excisional of a lesion in a keloid zone, it involves removal of additional tissue in an area already prone to tension and that is its disadvantage.

\section{Geometric broken-line closure (GBLC)}

Any scar revision technique must be based on risk/reward assessment. Some authors have suggested that scars greater than $2 \mathrm{~cm}$ in length or scars greater than $2 \mathrm{~mm}$ in width can be improved by geometric broken line closures [38]. One of the first people to describe Geometric Broken Line Closure (GBLC) was Wessberg in 1982 [39]. The technique of GBLC is as the name indicates-the scar is excised using geometric lines, drawn in such a fashion that triangles, rectangles, and squares are created in a random pattern (Figure 2) The main rationale in this technique is that converts a long, easily visible scar into a scar broken up into multiple short segments, and it is said that the scar becomes less apparent because the human eye has more difficulty tracking an irregular, multiply segmented line as opposed to a thicker straight line [40]. Studies have been done on presternal scars after cardiothoracic surgery to understand this predisposition to cause hypertrophic scarring, with studies confirming that scars on the sternum especially in women, tend to hypertrophy (even when there is no keloid tendency) after incisional wounds [41]. The main biomechanical issue on the sternal region is that the tension acts equally in all directions and this results in a higher risk of hypertrophic scarring [42]. In other areas on the body close to 
bone, skin exhibits not just anisotropy, but also orthotropy i.e. directional symmetry [43]. This degree of symmetry with respect to two normal planes is thought to be due to the preferential orientation of collagen fibres [7]. Breaking up a scar in smaller segments in differing directions therefore helps reduce the pull on the scar, thereby reducing the risk of hypertrophic scar formation.

But the GBLC is problematic outside the face region, from a technical point of view. For a start, it is usually employed to correct existing scars, not prevent them, and it is generally accepted among plastic surgeons "that the scar should be greater than 30 degrees off the RSTL" [44]. As we are discussing the use of zigs and zags in excisional surgery to reduce the risk of hypertrophic and keloid scarring, it seems out of place. However, the clincher seems to be this for an area like the sternum that is already prone to problematic scarring-as Shockley notes, "Because additional excision of normal tissue is required, the GBLC technique should only be considered in areas where there is sufficient skin redundancy and elasticity for closure without tension" [40]. The dermal structures of the chest and sternum by themselves confer an additional risk of scarring. As noted in studies by other authors, the anterior chest is the most frequent keloid-bearing site on the body; however, the anterior chest is not the site with the most frequent stretching/contraction-suggesting that other than skin mobility, it is indeed high tension with cyclical stretching that matters the most [15]. Other than respiration, the tension caused by coughing may also cause wound problems. It has been noted that a normal cough reaches $100 \mathrm{~mm} \mathrm{Hg}$, producing a force of $56 \mathrm{~kg}$, whereas maximal coughing can generate a pressure of $300 \mathrm{~mm}$ $\mathrm{Hg}$, thereby producing a force of $168 \mathrm{~kg}$ [45]. Others have developed mathematical models of sternotomy wounds to calculate the force generated by coughing and other stressors on a chest wound [46]:

$$
\mathrm{T}=\mathrm{rlP}=0.17 \mathrm{~m} \times 0.25 \mathrm{~m} \times 5.6 \mathrm{kPa}=238 \mathrm{~N} \sim 24 \mathrm{~kg}
$$

The chest is also a unique location from a biodynamic point of view because when people pull their chest in, the horizontal stretching/contraction rates are greater than the vertical; whereas, when people raise their hands, the vertical and oblique stretching rates are greater than the horizontal rates and this creates both constant and variable tension [15]. And, given we have been discussing that reduction of tension is the most important factor in reducing scarring, given the multi-directional stressors, it is especially important.

\section{The Simple Zigzag to Reduce Tension over Keloid Zones:}

A review undertaken of the different zigs and zags in use to improve scarring demonstrated the benefits of breaking up a scar into smaller segments. However, when used during primary closure, the techniques have some clear differences-the Z-plasty is all about angles, degrees of rotation and lengthening (Figure 4 and Figure 5), while the W-plasty and the geometric broken line closure involve cutting out additional tissue on both sides of the wound (Figure 3); The geometric broken line closure is difficult to perform during a primary elliptical excision and more suited to a scar revision of a thick cicatrix. The author therefore pondered if using a simple zig zag would be of benefit during primary elliptical 


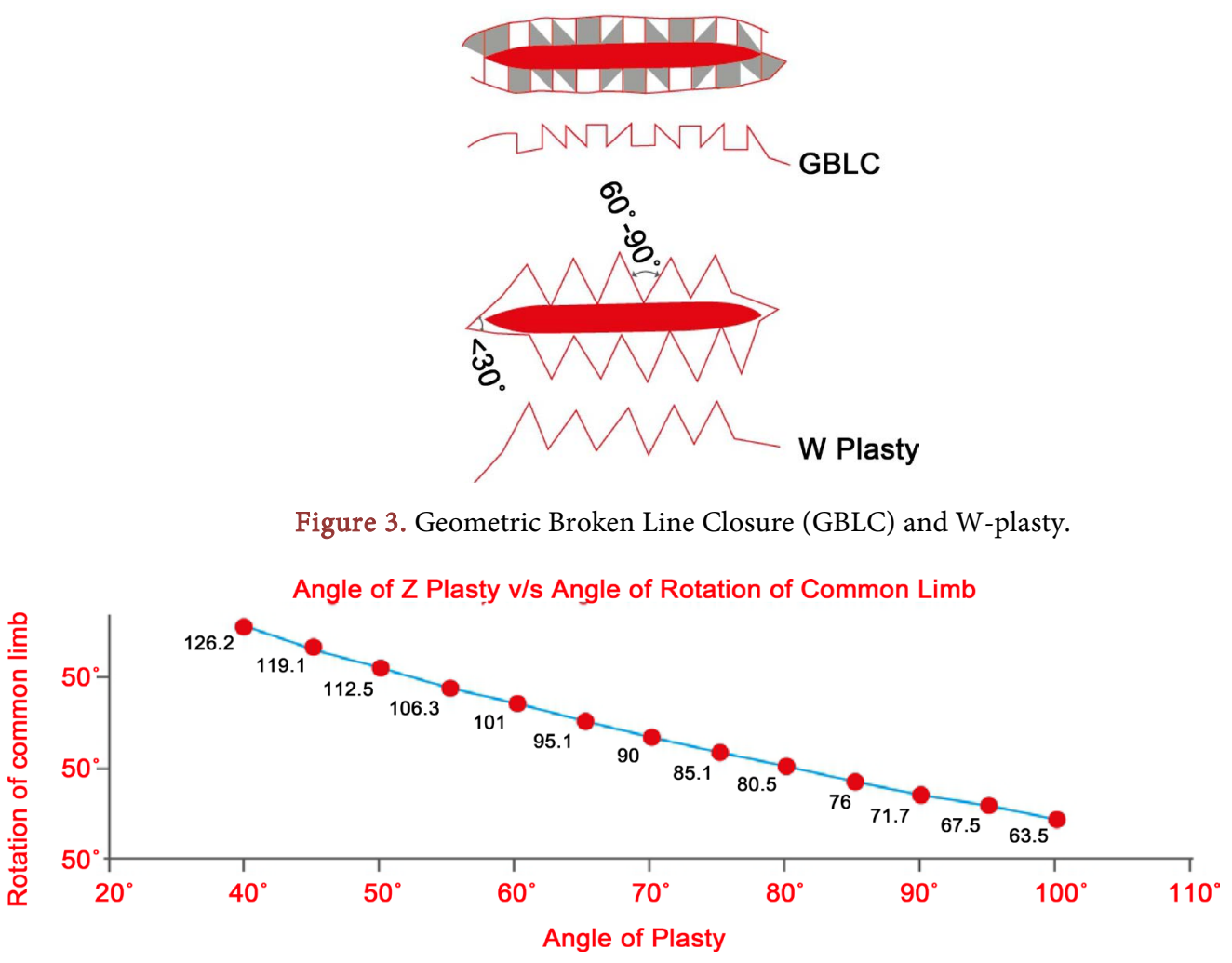

Figure 4. Z-plasty: angles and degrees of rotation.

$30^{\circ}$-angle z-plasty
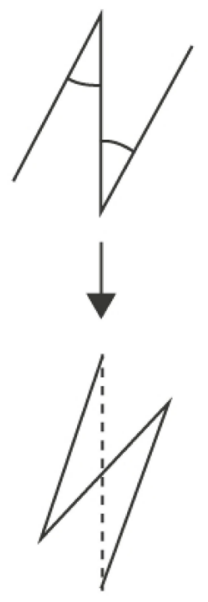

$25 \%$ length gain $45^{\circ}$-angle z-plasty
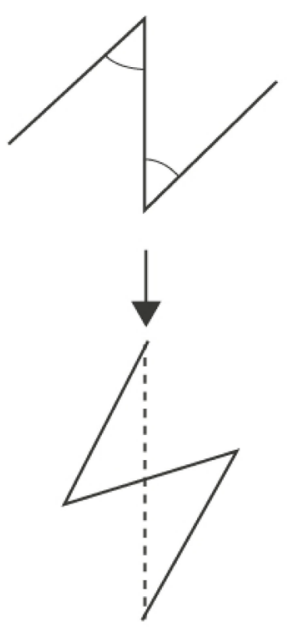

$50 \%$ length gain $60^{\circ}$-angle z-plasty
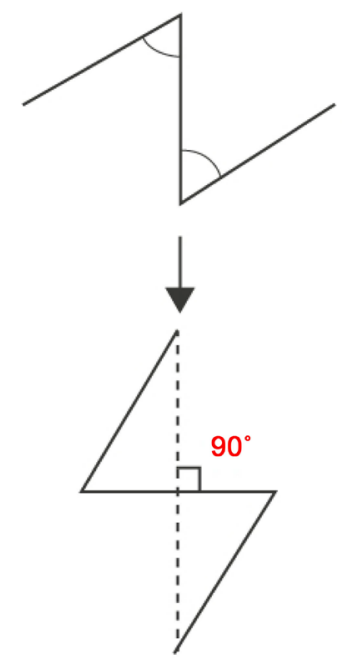

$75 \%$ length gain

Figure 5. Z-plasty: Angles and lengthening that occurs.

excision in a keloid-prone zone? There were two questions that needed answering:

1) Would a zigzag excision cause a reduction in mechanical forces which we already know is the major factor in fibro-proliferative processes that cause tissue fibrosis and hypertrophic scarring?

2) How does a zigzag compare biomechanically with a Z-plasty i.e. are all zig- 
zags created equal?

\section{Materials and Methods}

A series of 30 elliptical wounds created on pigskin were assigned into three groups of 10 each. Each comparison was done on identical pigskin i.e. the same animal. 10 standard elliptical closures, $10 \mathrm{Z}$-plasties of $30^{\circ}$ and 10 simple zigzag excisions were done (Figure 2 and Figure 6). The simple zigzag also had a $30^{\circ}$ angle in our study. Tension measurements were taken using a previously described and studied tensiometer [47]. The first reading was at the midpoint because authors have previously noted that the closing tension perpendicular to any linear incision is a function of the incision's length, varying symmetrically, and is maximal at the midpoint of the length [48]. To obtain a clear understanding, readings were taken at three points (marked 1, 2, 3 in Figure 6). These points were-the midpoint of the ellipse where tension was expected to be

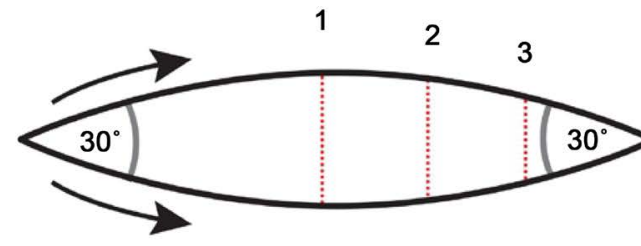

\begin{tabular}{|r|r|r|r|}
\hline 1 & 2.3 & 0.9 & 0.1 \\
\hline 2 & 2.0 & 1.0 & 0.5 \\
\hline 3 & 2.2 & 1.0 & 0.5 \\
\hline 4 & 1.8 & 1.0 & 0.1 \\
\hline 5 & 1.9 & 0.9 & 0.1 \\
\hline 6 & 2.3 & 1.1 & 0.2 \\
\hline 7 & 1.9 & 0.9 & 0.3 \\
\hline 8 & 2.3 & 1.0 & 0.2 \\
\hline 9 & 1.0 & 0.9 & 0.3 \\
\hline 10 & 2.0 & 1.0 & 0.5 \\
\hline
\end{tabular}

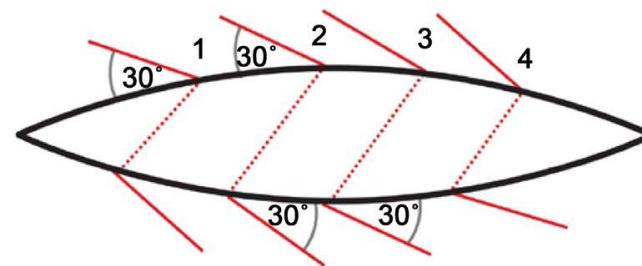

\begin{tabular}{|r|r|r|r|}
\hline 1 & 2.0 & 1.8 & 1.6 \\
\hline 2 & 1.8 & 1.6 & 1.4 \\
\hline 3 & 2.0 & 1.6 & 1.6 \\
\hline 4 & 2.0 & 1.8 & 1.8 \\
\hline 5 & 1.8 & 1.8 & 1.5 \\
\hline 6 & 1.7 & 1.7 & 1.6 \\
\hline 7 & 1.9 & 1.8 & 1.8 \\
\hline 8 & 1.9 & 1.8 & 1.7 \\
\hline $\mathbf{9}$ & 1.7 & 1.8 & 1.6 \\
\hline 10 & 1.4 & 1.4 & 1.2 \\
\hline
\end{tabular}

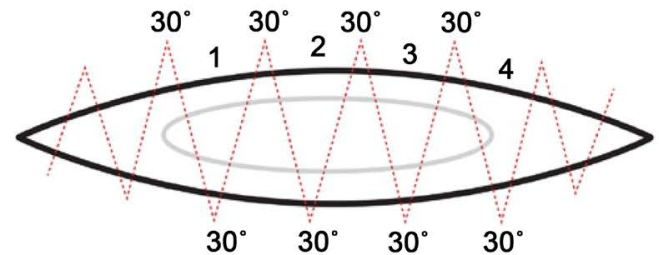

\begin{tabular}{|r|r|r|r|}
\hline 1 & 2.0 & 1.9 & 1.9 \\
\hline 2 & 1.8 & 1.7 & 1.7 \\
\hline 3 & 1.5 & 1.5 & 1.5 \\
\hline 4 & 0.9 & 0.8 & 0.8 \\
\hline 5 & 1.0 & 0.8 & 0.8 \\
\hline 6 & 1.6 & 1.5 & 1.5 \\
\hline 7 & 1.3 & 1.1 & 1.1 \\
\hline 8 & 1.6 & 1.5 & 1.5 \\
\hline 9 & 1.2 & 1.0 & 1.0 \\
\hline 10 & 1.0 & 0.9 & 0.9 \\
\hline
\end{tabular}

Figure 6. Study comparing wound tension in different closures-simple ellipse, Z-plasty and simple zigzag and points 1, 2 and 3. Forces measured in Newtons (N). 
maximal, one end of the excision and a third reading taken midway between the two points just mentioned.

The tension measurements were noted, as was any lengthening that occurred of the wound. The results were overseen by the mathematical sciences and statistics department who performed a detailed statistical analysis.

\section{Results}

Measurements of tension taken were as follows in Newtons (N) (Figure 6):

$$
\begin{aligned}
& \mathrm{m} 1 \text { (simple ellipse })=(2.3,2.0,2.2,1.8,1.9,2.3,1.9,2.3,1.0,2.0) \\
& \mathrm{m} 2(\text { Z-plasty })=(2.0,1.8,2.0,2.0,1.8,1.7,1.9,1.9,1.7,1.4) \\
& \mathrm{m} 3(\text { simple zigzag })=(2.0,1.8,1.5,0.9,1.0,1.6,1.3,1.6,1.2,1.0)
\end{aligned}
$$

Mean tension measurements $(\mathrm{N})$ were least in the simple zigzag:

$$
\begin{array}{ll}
\text { mean }(\mathrm{m} 1) & 1.97 \\
\text { mean }(\mathrm{m} 2) & 1.82 \\
\text { mean }(\mathrm{m} 3) & 1.39
\end{array}
$$

In the case of the simple elliptical closure or the simple zigzag excision, no lengthening of the wound was noted. In the Z-plasty lengthening was noted, in keeping with already established angle-to-lengthening expectations. The tension measurements were taken prior to closure and summarized in the table.

In the case of the simple elliptical excision, as expected, tension was maximal at the midpoint and very low at the ends. In the case of the simple zigzag, there was a reduction in tension at the midpoint, with a levelling out of forces required to close the wound. In a Z-plasty, there appeared to be more equalization of tension across the wound, however the tension did not lower markedly at the ends of the wound and the midpoint tension was higher than that of a simple zigzag.

The statistics team applied the Welch Two Sample t-test to compare the data between each of the samples.

Welch Two Sample t-test comparing data $\mathrm{m} 1$ and $\mathrm{m} 2$

$$
\mathrm{t}=1.0989, \mathrm{df}=12.966, \mathrm{p} \text {-value }=0.2918
$$

alternative hypothesis: true difference in means is not equal to 0

95 percent confidence interval:

$-0.1449787 \quad 0.4449787$

sample estimates:

mean of $\mathrm{x} \quad$ mean of $\mathrm{y}$

$1.97 \quad 1.82$

Welch Two Sample t-test comparing data: $\mathrm{m} 1$ and $\mathrm{m} 3$

$$
\mathrm{t}=3.419, \mathrm{df}=17.953, \mathrm{p} \text {-value }=0.003069
$$

alternative hypothesis: true difference in means is not equal to 0

95 percent confidence interval:

$0.2235329 \quad 0.9364671$

sample estimates: 
mean of $\mathrm{x} \quad$ mean of $\mathrm{y}$

$1.97 \quad 1.39$

Welch Two Sample t-test comparing data $\mathrm{m} 2$ and $\mathrm{m} 3$

$$
\mathrm{t}=3.2819, \mathrm{df}=13.341, \mathrm{p} \text {-value }=0.005771
$$

alternative hypothesis: true difference in means is not equal to 0

95 percent confidence interval:

$0.147679 \quad 0.712321$

sample estimates:

mean of $\mathrm{x} \quad$ mean of $\mathrm{y}$

$1.82 \quad 1.39$

The results show clearly that using a simple zigzag reduces tension across the midpoint of the scar more effectively than a Z-plasty $(p=0.005771)$, and much more effectively than a simple elliptical excision where tension is highest at the midpoint ( $\mathrm{p}=0.003069)$. There was no statistically significant reduction in tension between a Z-plasty and a simple excision $(\mathrm{p}=0.2918)$ in this study.

\section{Discussion}

The techniques of breaking up a scar or incision line by using zigs and zags, in a means to reduce scarring, are not new. However, each of these techniques has specific advantages and disadvantages.

In this study, the Z-plasty did not show a significant reduction of tension when compared to standard elliptical primary closure at the midpoint. This is to be expected as the Z-plasty, by nature of its design, appears to equalize tension across the wound and lengthens the wound. The midpoint scar reduction is a key aim of reducing scarring, especially as authors have shown the link between such tension and scar formation [10].

The simple $30^{\circ}$ zigzag not only reduces tension across the wound, but also avoids lengthening the scar as much as a Z-plasty. The Z-plasty may be preferable over contractures, but as a primary procedure during excision of a lesion to avoid hypertrophic scarring by reducing wound tension, we found the simple zigzag proved a more effective technique. Given the midpoint is where the lesion to be excised lies, the simple zigzag closure ends up slightly flattened at the midpoint as seen in the clinical photos (Figure 7). In the image pictured the lesion was quite narrow in the horizontal plane, and therefore only two zigzags were possible; however, the wound closed under less tension than would be normally expected and there has been no hypertrophy of the scar. This was a patient who had ended up with keloid or hypertrophic scars on every previous excision on the trunk. At three months after surgery, she does not have any hypertrophy after the simple zigzag closure (Figure 7).

The study had to be on pigskin so that we could test each pattern on tissue with almost identical characteristics. It would not have been possible to design a clinical study on human patients to compare all the three types of closures on a single patient. However, the study provided valuable insight into the biomechanics of zigs and zags, their role in reducing wound tension, and thereby scarring. 


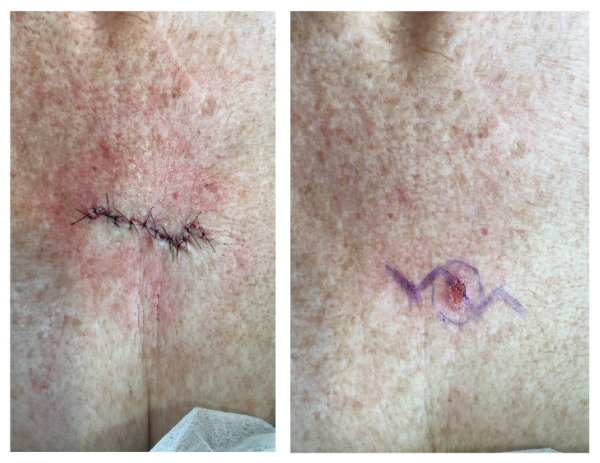

Figure 7. Clinical photo showing zigzag excision to reduce tension.

The author would like to point out an observation that when a $30^{\circ}$ angle is used, it functions rather like a Burow's triangle. Burow's triangles, because of the small advancement involved have been noted to reduce wound tension [49] and this is partly how the simple zigzag works to reduce tension. The zigzag also has the advantage of breaking up the linear scar into many small segments, a method well established in plastic surgical practice to reduce scarring [50].

In a simple elliptical excision, the tension is maximal at the midpoint and tapers off at the ends. In areas like the sternum, and other keloid-prone regions, breaking up of scars to reduce tension is advisable and as noted in this study, the simple zigzag excision proves an extremely useful option. The limitation of this study is that we have not reviewed the long-term results i.e. future scar formation. However, it is already well known that the wound-closing tension is a major factor in scar formation, and breaking up a linear scar in this zig-zag fashion has shown its ability to reduce wound tension significantly. We see this study and review as a good starting point to undertake further studies in the keloid triangles of human subjects.

\section{Acknowledgements}

This paper resulted from a study that forms part of my Ph.D research project at the University of Queensland's School of Medicine and I would like to acknowledge my supervisors, Assoc. Professor Cliff Rosendahl, University of Queensland, and Professor John Windsor, Faculty of Surgery, University of Auckland. I would also like to thank Ryan Butler for help with illustrations and photography. And finally I would like to thank and acknowledge Dr Robin Hankin, computational statistician at the Auckland University of Technology for his help with detailed statistical analyses.

\section{Conflicts of Interest}

There are no conflicts of interest to declare.

\section{Financial Support and Sponsorship (Optional)}

There are no sponsorships or financial support to declare.

I can confirm I am the sole and corresponding author and all ethics approvals for 
any studies have been approved by the relevant authorities: New Zealand Health and Disability Ethics Committees (HDEC Reference number 15/CEN/113); Australia: University of Queensland Institutional Human Ethics (Approval No. 2015001550).

\section{Funding}

There is no external funding or any conflicts of interests, or competing interests to declare. Any help received, by way of help with illustrations etc. has been acknowledged in the article.

\section{References}

[1] West, B.R., Applebaum, H. and Edgerton, B.W. (1994) A Better Incision for Pectus Excavatum Repair: Avoiding the Keloid Triangle. Pediatric Surgery International, 9, 301. https://doi.org/10.1007/BF00832265

[2] Duscher, D., Maan, Z.N., Wong, V.W., et al. (2014) Mechanotransduction and Fibrosis. Journal of Biomechanics, 47, 1997-2005. https://doi.org/10.1016/j.jbiomech.2014.03.031

[3] Alenghat, F.J. and Ingber, D.E. (2002) Mechanotransduction: All Signals Point to Cytoskeleton, Matrix, and Integrins. Science Signaling, 119, pe6. https://doi.org/10.1126/stke.2002.119.pe6

[4] Gurtner, G.C., Werner, S., Barrandon, Y. and Longaker, M.T. (2008) Wound Repair and Regeneration. Nature, 453, 314-321. https://doi.org/10.1038/nature07039

[5] Paul, S.P. (2016) The Golden Spiral Flap: A New Flap Design that Allows for Closure of Larger Wounds under Reduced Tension-How Studying Nature's Own Design Led to the Development of a New Surgical Technique. Frontiers in Surgery, 3, 63. https://doi.org/10.3389/fsurg.2016.00063

[6] Garikipati, K. (2009) The Kinematics of Biological Growth. Applied Mechanics Reviews, 62, 030801.

[7] Wang, Y. and Wang, N. (2009) FRET and Mechanobiology. Integrative Biology (Camb), 1, 565-573. https://doi.org/10.1039/b913093b

[8] Ingber, D.E. (1998) The Architecture of Life. Scientific American, 278, 48-57. https://doi.org/10.1038/scientificamerican0198-48

[9] Aarabi, S., Bhatt, K.A., Shi, Y., Paterno, J., Chang, E.I., Loh, S.A., Holmes, J.W., Longaker, M.T., Yee, H. and Gurtner, G.C. (2007) Mechanical Load Initiates Hypertrophic Scar Formation through Decreased Cellular Apoptosis. The FASEB Journal, 21, 3250-3261. https://doi.org/10.1096/fj.07-8218com

[10] Gurtner, G.C., Dauskardt, R.H., Wong, V.W., Bhatt, K.A., Wu, K., Vial, I.N., Padois, K., Korman, J.M. and Longaker, M.T. (2011) Improving Cutaneous Scar Formation by Controlling the Mechanical Environment: Large Animal and Phase I Studies. Annals of Surgery, 254, 217-225. https://doi.org/10.1097/SLA.0b013e318220b159

[11] Goto, M., Ikeyama, K., Tsutsumi, M., Denda, S. and Denda, M. (2010) Calcium Ion Propagation in Cultured Keratinocytes and Other Cells in Skin in Response to Hydraulic Pressure Stimulation. Journal of Cellular Physiology, 224, 229-233.

[12] Lemmon, C.A., Chen, C.S. and Romer, L.H. (2009) Cell Traction Forces Direct Fibronectin Matrix Assembly. Biophysical Journal, 96, 729-738.

https://doi.org/10.1016/j.bpj.2008.10.009 
[13] Deitch, E.A., Wheelahan, T.M., Rose, M.P., Clothier, J. and Cotter, J. (1983) Hypertrophic Burn Scars: Analysis of Variables. The Journal of Trauma: Injury, Infection, and Critical Care, 23, 895-898. https://doi.org/10.1097/00005373-198310000-00009

[14] Akaishi, S., Akimoto, M., Ogawa, R. and Hyakusoku, H. (2008) The Relationship between Keloid Growth Pattern and Stretching Tension: Visual Analysis Using the Finite Element Method. Annals of Plastic Surgery, 60, 445-451. https://doi.org/10.1097/SAP.0b013e3181238dd7

[15] Ogawa, R., et al. (2012) The Relationship between Skin Stretching/Contraction and Pathologic Scarring: The Important Role of Mechanical Forces in Keloid Generation. Wound Repair and Regeneration, 20, 149-157. https://doi.org/10.1111/j.1524-475X.2012.00766.x

[16] Shockley, W.W. (2011) Scar Revision Techniques: Z-Plasty, W-Plasty, and Geometric Broken Line Closure. Facial Plastic Surgery Clinics of North America, 19, 455463. https://doi.org/10.1016/j.fsc.2011.06.002

[17] Stratton, G.M. (1902) Eye-Movements and the Aesthetics of Visual Form. Philosophical Studies, 20, 336-359.

[18] Ito, H. and Yang, X. (2013) A Short Line Segment Squirms along a Zigzag Line. i-Perception, 4, 141-143. https://doi.org/10.1068/i0573sas

[19] Bar, M. and Neta, M. (2006) Visual Elements of Subjective Preference Modulate Amygdala Activation. Neuropsychologia, 45, 2191-2200. https://doi.org/10.1016/j.neuropsychologia.2007.03.008

[20] Gómez-Puerto, G., Munar, E. and Nadal, M. (2016) Preference for Curvature: A Historical and Conceptual Framework. Frontiers in Human Neuroscience, 9, 712. https://doi.org/10.3389/fnhum.2015.00712

[21] Horner, W.E. (1837) Clinical Report on the Surgical Department of the Philadelphia Hospital, Blockley for the Months of May, June and July 1837. The American Journal of the Medical Sciences, 21, 105-106.

[22] Denonvilliers, C.P. (1856) Blepharoplastie. Bulletin of the Society of Chirurgie, Paris, 7, 243-245.

[23] Borges, A.F. and Gibson, T. (1973) The Original Z-Plasty. British Journal of Plastic Surgery, 26, 237-246. https://doi.org/10.1016/0007-1226(73)90008-8

[24] McCurdy, S.L. (1904) Plastic Operations to Elongate Cicatricial Contractions across Joints. Cleveland Medical Journal, 1, 121.

[25] Limberg, A.A. (1946) Mathematical Principles of Local Plastic Procedures on the Surface of the Human Body. Megriz, Leningrad.

[26] Limberg, A.A. (1966) Design of Local Flaps. In: Gibson, T., Ed., Modern Trends in Plastic Surgery, Vol. 2, Butterworths, London.

[27] Limberg, A.A. (1929) Skin Plastic and Shifting Triangle Flaps in Collection of Scientific Works. Leningrad Trauma Inst, 862.

[28] Limberg, A.A. (1967) Planimetrie und Stereometrie der Hautplastik. Gustav Fischer Verlag, Jena.

[29] Ellur, S. and Guido, N.L. (2009) A Mathematical Model to Predict the Change in Direction of the Common Limb in Z-Plasty. Indian Journal of Plastic Surgery, 42, 82-84. https://doi.org/10.4103/0970-0358.53015

[30] Rajabi, A., Dolovich, A.T. and Johnston, J.D. (2015) From the Rhombic Transposition Flap toward Z-Plasty: An Optimized Design Using the Finite Element Method. Journal of Biomechanics, 48, 3672-3678.

https://doi.org/10.1016/j.jbiomech.2015.08.021 
[31] Borges, A.F. (1979) W-Plasty. Annals of Plastic Surgery, 3, 153-159. https://doi.org/10.1097/00000637-197908000-00012

[32] Rossoe, E.W.T., Tebcherani, A.J., Sittart, J.A. and Cezar Pires, M. (2011) Actinic Cheilitis: Aesthetic and Functional Comparative Evaluation of Vermilionectomy Using the Classic and W-Plasty Techniques. Anais Brasileiros de Dermatologia, 86, 65-73. https://doi.org/10.1590/S0365-05962011000100008

[33] Han, S., Han, U., et al. (2008) W-Plasty Technique in Tracheal Reconstruction: A New Technique? European Surgical Research, 41, 319-323. https://doi.org/10.1159/000155897

[34] Beraldo, S., Titley, G. and Allan, A. (2006) Use of W-Plasty in Stenotic Stoma: A New Solution for an Old Problem. Colorectal Disease, 8, 715-716. https://doi.org/10.1111/j.1463-1318.2006.01020.x

[35] Murakami, M., Oki, K., et al. (2010) The Effect of W-Plasty on Cheek Rotation Flap. Eplasty, 10, e8.

[36] Gómez, A. and Pomares, A. (2016) Primary W-Plasty Closure for Surgical Repair of the Injured Lip. Journal of Craniofacial Surgery, 27, e57-e58.

https://doi.org/10.1097/scs.0000000000002311

[37] Elkhatib, H.A. (2016) The Extended Running W-Plasty: An Additional Tool for Simultaneous Reduction of the Hypertrophied Labia Minora and Redundant Clitoral Hood. Plastic and Aesthetic Research, 3, 359-363.

https://doi.org/10.20517/2347-9264.2016.41

[38] Rodgers, B.A., Williams, E.F. and Hove, C.R. (2001) W-Plasty and Geometric Broken Line Closure. Facial Plastic Surgery, 17, 239-244. https://doi.org/10.1055/s-2001-18829

[39] Wessberg, G.A. and Hill, S.C. (1982) Revision of Facial Scars with Geometric Broken Line Closure. Journal of Oral and Maxillofacial Surgery, 40, 492-496. https://doi.org/10.1016/0278-2391(82)90010-6

[40] Visscher, M.O., Bailey, J.K., Hom, D.B. (2014) Scar Treatment Variations by Skin Type. Facial Plastic Surgery Clinics of North America, 22, 453-462. https://doi.org/10.1016/j.fsc.2014.04.010

[41] Elliot, D., Cory-Pearce, R. and Rees, G.M. (1985) The Behaviour of Presternal Scars in a Fair-Skinned Population. Annals of The Royal College of Surgeons of England, 67, 238-240.

[42] Meyer, M. and McGrouther, D.A. (1991) A Study Relating Wound Tension to Scar Morphology in the Pre-Sternal Scar Using Langers Technique. British Journal of Plastic Surgery, 44, 291-294. https://doi.org/10.1016/0007-1226(91)90074-T

[43] Lanir, Y. and Fung, Y.C. (1974) Two-Dimensional Mechanical Properties of Rabbit Skin. I. Experimental System. Journal of Biomechanics, 7, 29-34. https://doi.org/10.1016/0021-9290(74)90067-0

[44] Lanir, Y. and Fung, Y.C. (1974) Two-Dimensional Mechanical Properties of Rabbit Skin. II. Experimental Results. Journal of Biomechanics, 7, 171-182. https://doi.org/10.1016/0021-9290(74)90058-X

[45] Murray, J.F. and Nadel, J.A. (1994) Textbook of Respiratory Medicine. 2nd Edition, Vol. 1, WB Saunders, Philadelphia, 531-532.

[46] Lang-Lazdunski, L., Heurteaux, C. and Lazdunski, M. (1999) Measurement of Chest Wall Forces on Coughing with the Use of Human Cadavers. The Journal of Thoracic and Cardiovascular Surgery, 118, 1157. https://doi.org/10.1016/S0022-5223(99)70128-5

[47] Paul, S.P., Matulich, J. and Charlton, N. (2016) A New Skin Tensiometer Device: 
Computational Analyses to Understand Biodynamic Excisional Skin Tension Lines. Scientific Reports, 6, Article No. 30117. https://doi.org/10.1038/srep30117

[48] Blinman, T. (2010) Incisions Do Not Simply Sum. Surgical Endoscopy, 24, 17461751. https://doi.org/10.1007/s00464-009-0854-z

[49] Baker, S.R. (2014) Local Flaps in Facial Reconstruction: Expert Consult. 3rd Edition, Elsevier Health Sciences, Philadelphia, PA, 108.

[50] Sharma, M. and Wakure, A. (2013) Scar Revision. Indian Journal of Plastic Surgery, 46, 408-418.

Submit or recommend next manuscript to SCIRP and we will provide best service for you:

Accepting pre-submission inquiries through Email, Facebook, LinkedIn, Twitter, etc. A wide selection of journals (inclusive of 9 subjects, more than 200 journals) Providing 24-hour high-quality service User-friendly online submission system Fair and swift peer-review system Efficient typesetting and proofreading procedure Display of the result of downloads and visits, as well as the number of cited articles Maximum dissemination of your research work

Submit your manuscript at: http://papersubmission.scirp.org/ Or contact ss@scirp.org 